\title{
Predicting the workload in urban general practice in The Netherlands from Jarman's indicators of deprivation at patient level
}

\author{
Sijmen A Reijneveld
}

\begin{abstract}
Study objective - General practitioners (GPs) working in deprived areas supposedly have higher workloads. In the UK, this has led to a higher payment per patient from deprived areas, based on eight indicators of deprivation proposed by Jarman. This paper aimed to examine the applicability of the Jarman index (indicators and attached weights) at patient level in an urban GP setting outside the UK.

Design - Data on all GP contacts were collected from 5121 residents aged 16 and over by interview.

Setting - Amsterdam, The Netherlands, 1992-93.

Main results - Results showed that six out of eight of the Jarman indicators of deprivation were indeed associated with higher GP contact rates in adults in Amsterdam, though some of them without statistical significance. The relative importance of the indicators, however, differed largely from Jarman's weights. In particular, people in poor housing, unskilled earners, and people born in a foreign country had higher contact rates. Furthermore, some indicators were highly inter-related at patient level.

Conclusions - It is concluded that most of the Jarman indicators can be used to predict Amsterdam GP workload at patient level, but that their relative weights should be adapted for this aim. The applicability of the Jarman index (indicators and attached weights) in other European countries requires additional study.
\end{abstract}

( $(\mathcal{F}$ Epidemiol Community Health 1996;50:541-544)

Amsterdam Municipal

Health Service,

Department of

Epidemiology,

PO Box 20244,

1000 HE Amsterdam,

The Netherlands and

Academic Medical

Centre,

University of

Amsterdam,

Department of Social

Medicine, Amsterdam,

The Netherlands

$S$ A Reijneveld

Correspondence to

Dr S A Reijneveld,

Amsterdam Municipal

Health Service.

Accepted for publication April 1996

The higher workload of general practitioners (GPs) in deprived areas of the UK, especially London, has led to a higher payment for patients from these areas. Payments are based on eight indicators of area deprivation, proposed by Jarman on the basis of a survey among GPs. ${ }^{1}$ The predictive ability of the score on these indicators for GP workload has been debated intensely. ${ }^{2-4}$ There are criticisms of the choice of indicators for extra workload, the use of indicators of area deprivation instead of individual characteristics, and the weighting and further handling of the eight indicators of area deprivation included in the Jarman index. $^{23}$
Some of these criticisms can be traced back to the way in which the Jarman index was composed. Indicators were selected on the basis of comments from London GPs and health care organisations, made to the Acheson Committee $^{5}$ on the structure of primary health care in inner London. ${ }^{6}$ Next, weights were derived from a survey among English and Welsh GPs on the relative importance of these indicators. ${ }^{1}$ It is probable that both surveys yielded results on characteristics of individual patients which are associated with surplus workload and not on characteristics of the areas from which they come. Furthermore, indicators have been selected with regard to problems in London health care and may thus be biased to deprivation in urban areas, ${ }^{3}$ or even London only. ${ }^{7}$ Finally, concerning urban GP workload, a comparison of the weights of the Jarman index with the actually measured workload is lacking.

A recent, large, population survey in Amsterdam offered the opportunity to examine the applicability of the Jarman index (indicators and attached weights) in an urban, European GP setting outside the UK, in terms of the number of GP contacts for individual patients. ${ }^{4}$ Though Amsterdam is much smaller than London, the complexity of its health care as well as the size of socioeconomic health differences are comparable. ${ }^{8}$ Furthermore, GPs have a central position in health care, both in The Netherlands and in the UK. Workload is also supposed to be higher in deprived urban areas of The Netherlands. ${ }^{910}$ An additional GP payment for patients from these areas has been agreed ${ }^{10}$ and its implementation has begun. ${ }^{11}$ Whether, and to what extent, the position of individual Amsterdam patients in terms of Jarman indicators predicts their GP contact rate was studied in order to examine the applicability of Jarman indicators in this context.

\section{Methods}

Data on the number of contacts with a GP during the preceding two months and on socioeconomic background were obtained from 5121 subjects by face to face interviews. This survey was based on a random sample $(n=$ 8335) from the adult, non-institutionalised Amsterdam population. It was drawn from the municipal population register after stratification for age $(16-34,35-64$, and $\geq 65$ years) and borough (17 boroughs). The aim of the stratification was to interview a more or less equal number of respondents for each age and borough group. Interviews were conducted 
Table 1 Number of additional contacts due to Jarman indicators at the individual or household level in a simple and mutually adjusted model

\begin{tabular}{|c|c|c|c|}
\hline \multirow[b]{2}{*}{ Indicator (weight in farman score) } & \multirow[b]{2}{*}{ No† } & \multicolumn{2}{|c|}{ No of additional contacts* ( $p$ value) } \\
\hline & & Simple $\ddagger$ & Adjusted $\$$ \\
\hline $\begin{array}{l}\text { Single pensioner }(6.62) \\
\text { Child aged }<5 \text { y in family }(4.64) \\
\text { Unskilled or semiskilled earner }(3.74) \\
\text { Unemployed ( } 3.34) \text { (not available for work) } \\
\text { Single parent }(3.01) \\
\text { Poor quality housing }(2.88) \\
\text { Changed address }(2.68) \\
\text { Born in foreign country }(2.50) \\
\text { Age } 65-74 \text { years } \\
\quad \geq 75 \text { years }\end{array}$ & $\begin{array}{r}350 \\
376 \\
897 \\
363(2282) \\
374 \\
1008 \\
297 \\
1160 \\
458 \\
319\end{array}$ & $\begin{array}{l}0.63(\mathrm{NS}) \\
0.45(\mathrm{NS}) \\
1.14(<0.001) \\
-0.35(0.74)(<0.001) \uparrow \\
0.74(<0.05) \\
1.32(<0.001) \\
-0.66(\mathrm{NS}) \\
0.99(<0.001) \\
1.26(<0.001) \\
2.67\end{array}$ & $\begin{array}{l}-0.03 \text { (NS) } \\
0.10 \text { (NS) } \\
0.85(<0.001) \\
-0.74(0.64)(<0.001) 9 \\
0.35 \text { (NS) } \\
1.24(<0.001) \\
-0.86(<0.05) \\
0.85(<0.001) \\
0.69(<0.001) \uparrow \\
1.90\end{array}$ \\
\hline
\end{tabular}

* Compared with the average number of contacts $(4.62 / y)$

Weighted; no or invalid information on GP contact rate was obtained from 39 respondents.

Each analysis includes age ( 65 and $\geq 75 \mathrm{y}$ ), type of insurance, and the variable of interest.

Each analysis is adjusted for type of insurance and all other variables in the table.

I This $\mathrm{p}$ value concerns the analysis of this variable in three categories.

from June 1992 to June 1993, to control for seasonal differences in health and the use of health care services.

The overall response rate of the survey was $61.4 \%$. To check for potential selection bias, respondents and non-respondents were compared in terms of eight characteristics which were known concerning all of them. These were age, gender, marital status, family composition, country of birth, borough, year of settlement in Amsterdam, and month of interview. ${ }^{12}$ This comparison did not show any difference, ${ }^{13}$ which indicates that the group of respondents is representative of the non-institutionalised adult Amsterdam population. ${ }^{12}$

Data on the Jarman indicators of deprivation as obtained all pertain to the interviewed person. Because our survey concerned persons of 16 and over, we have no information on one Jarman indicator, the under $5 \mathrm{~s}$. Instead, we used the presence of an under 5 in the family, assuming that such a child will always be accompanied by an adult during a GP visit. Furthermore, two indicators differed from Jarman's set (our definition/Jarman's definition): poor quality housing (not wind and waterproof/ overcrowded), and changing address (to the city during last two years/any change during last year)

The mean number of contacts per year was computed per indicator by multiplying the number of contacts in the preceding two months by six, and adjusting for age as in the UK capitation formula. ${ }^{4} \mathrm{Next}$, the separate indicators were adjusted for all the other ones using multiple classification analysis. ${ }^{14}$ The relative contributions of the indicators in the first, simple model and in the second, adjusted model were then compared with those proposed by Jarman, by means of rank correlation. Finally, we tried to simplify the adjusted model by eliminating variables which did not contribute with statistical significance and by inclusion of age in more detail (10 categories instead of 3).

All analyses were adjusted for type of insurance (sick fund/privately insured), because this is known to have an independent impact on the use of GP care, ${ }^{15}$ and for the stratified sampling procedure. The distribution of GP contact rate data was highly skewed. Therefore, all analyses were repeated for the dichotomy "none/one or more contacts", using logistic regression, though this problem mainly pertains to small samples. Finally, we checked the influence of the type of health insurance on the Jarman indicators. All analyses were performed with the SPSS statistical package. ${ }^{14}$

\section{Results}

The mean number of GP contacts per year (95\% confidence interval (95\% CI)) was 4.62 $(4.42,4.83)$. Table 1 shows that contact rates were especially high among poorly housed people, among unskilled or semiskilled earners, and among people born in a foreign country. However, people who had recently changed address and who were unemployed had contact rates below average. With regard to the unemployed, this was mainly due to a high contact rate among those not available for work, for instance due to being a student, (early) retirement, house keeping, or working incapacity. These people were not looking for work and were not therefore registered as unemployed. The high contact rate among the "not available" group increased the average which caused unemployed people to have fewer contacts than average, but still 0.40 per year more than the employed. A mutual adjustment of the separate Jarman indicators led to smaller numbers of extra GP contacts for all indicators. In this case single pensioners had almost average contact rates too.

Rankings of variables in the simple and adjusted models were almost similar, but differed largely from the ranks of the weights in the Jarman formula (table 2). Rank correlations (R) between these two were -0.12 and -0.20 for the simple and the adjusted models respectively, which indicated a complete lack of similarity. Limitation of this analysis to the indicators which were measured completely according to Jarman's definition gave similar results. The same applied if, with regard to unemployment, yearly contact rates of the unemployed were compared with the contact rates of those available for work, instead of with the rates of all respondents.

Elimination of all three variables which did not influence contact rates with statistical significance scarcely changed the explanatory power of the model. Inclusion of age in more 
Table 2 Ranking of Farman indicators of deprivation according to the weights proposed by Farman, the simple model, the adjusted model, and an adjusted logistic regression model predicting any contact.

\begin{tabular}{|c|c|c|c|c|c|c|c|c|}
\hline \multirow[b]{2}{*}{ Variable } & \multicolumn{2}{|c|}{ Farman index } & \multicolumn{2}{|c|}{ Simple model* } & \multicolumn{2}{|c|}{ Adjusted model $\uparrow$} & \multicolumn{2}{|c|}{ Adjusted logistic regression model $\uparrow$} \\
\hline & Rank & Relative weight $\ddagger$ & Rank & Ratio of workload $\$$ & Rank & Ratio of workload & Rank & Odds ratio \\
\hline Single pensioner & 1 & 2.65 & 5 & 1.03 & 6 & 0.98 & 1 & 1.30 \\
\hline Child aged $<5 \mathrm{y}$ in family & 2 & 1.86 & 6 & 1.07 & 5 & 1.00 & 6 & 0.99 \\
\hline Unskilled or semiskilled worker & 3 & 1.50 & 2 & 1.23 & 2.5 & 1.17 & 4 & 1.23 \\
\hline Unemployed & 4 & 1.34 & 7 & 1.00 & 7 & 0.92 & 7 & 0.90 \\
\hline Single parent & 5 & 1.20 & 4 & 1.12 & 4 & 1.03 & 5 & 1.11 \\
\hline Poor quality housing & 6 & 1.15 & 1 & 1.27 & 1 & 1.26 & 2 & 1.29 \\
\hline Changed address & 7 & 1.07 & 8 & 0.88 & 8 & 0.79 & 8 & 0.80 \\
\hline Born in foreign country & 8 & 1.00 & 3 & 1.20 & 2.5 & 1.18 & 3 & 1.22 \\
\hline
\end{tabular}

* Each analysis includes age (65-74 and $\geq 75 y)$, type of insurance, and the variable of interest.

+ Each analysis is adjusted for age $(65-74$ and $\geq 75 y)$, type of insurance and all other variables in the table.

$\$$ Weight in the Jarman index, relative to the variable with the lowest weight.

$\S$ Ratio of work load due to (patients with) the variable concerned, compared to the average workload (4.62 contacts/y).

detail showed that contact rates increased steadily with advancing age. Furthermore, the importance of a recent change of address then decreased and was no longer statistically significant, but the importance of the other variables hardly changed.

All results were confirmed with logistic regression, using any contact as the outcome, except for the single pensioners; in the logistic model, single pensioners had the highest contact rate. Examination of the data showed that a rather large proportion of them visited a GP during the preceding two months, but usually only once. The rankings in the logistic regression of all other variables mirrored those on the average number of contacts, both for a simple logistic model (not shown) and for an adjusted logistic model (table 2).

Omission of the correction for type of insurance made some differences slightly larger, but yielded identical rankings. However, the type of health insurance seemed to modify the influence of country of birth, as was shown by a statistically significant first order interaction between these two variables. Further analysis showed that the additional contacts among people born outside The Netherlands mainly came from those with sick fund insurance.

\section{Discussion and conclusion}

Our analysis shows that six out of eight of the Jarman indicators of deprivation are indeed associated with higher GP contact rates among Amsterdam adults, though some of them are not statistically significant. The relative importance of the indicators differs largely from the experience of English and Welsh GPs, however. In particular, people who are poorly housed, unskilled earners, and people born in a foreign country have higher contact rates. Among the latter, the additional contacts mainly concern those with sick fund insurance. Furthermore, the contribution of all indicators to GP workload is smaller if they are adjusted for the other ones, which shows that they are strongly interrelated.

Our analysis concerns the average number of contacts, which may have two disadvantages. A first, statistical, disadvantage is that this measure is highly skewed which may corrupt the constructed model. However, logistic regression predicting the occurrence of any contact yields very similar results. Only the results concerning single pensioners are different, due to real differences between both measures. A second disadvantage is that we do not have information on the nature of contacts, which also influences workload. This concerns both the type of consultation (house calls versus surgery visits) and the kind of problems, for example, the occurrence of more severe health problems and of violence from patients. ${ }^{916}$ For instance, the higher ranking in the Jarman index of the under $5 \mathrm{~s}$ and single pensioners may be explained by such qualitative aspects. Most house calls in urban areas occur among young children and elderly people. ${ }^{17}$

Our study concerns indicators of deprivation at the individual level whereas in the UK these are used at area level; this may explain some of the differences we found. However, Professor Jarman derived the weights of the index from the responses of GPs to a questionnaire. ${ }^{1}$ It might be hypothesised that these responses applied at least partly to individual patients instead of to the areas in which these patients lived. In our data, both levels are interconnected too. GP contact rates diverge between Amsterdam boroughs with different degrees of deprivation and these differences are reduced largely if contact rates are adjusted for Jarman's indicators at the individual level. For instance, with regard to the proportion of households with a low income, an indicator of area deprivation commonly used in Amsterdam, ${ }^{18}$ differences in yearly GP contact rate are reduced from 4.31 in the most favourable quartile and 4.70 in the least favourable one, to 4.51 in both of them. This supports the validity of the Jarman indicators, though not of the attached weights.

Ben-Shlomo et al also predicted GP contact rates on the basis of Jarman indicators at individual or household level. ${ }^{4}$ Their analysis was thus potentially exposed to a cross-level bias ("ecological fallacy") similar to ours. ${ }^{19}$ It was based on the registration in 25 practices in England and Wales of all consultations over one year $(n=140050)$ and they gave an additional weight (2.5) to house calls. They found a ranking of the Jarman indicators which is similar to Jarman's one $(R=0.86)$, but differs appreciably from ours ( $R$ varying from -0.12 to -0.36 for the various models). Thus, in England and Wales the Jarman index (indicators and attached weights) seems to be valid for both urban and rural areas and for both the in- 
dividual and the area level, but the relative weights do not seem to apply to the individual level in this urbanised Dutch area.

The differing weights may be partly explained by the fact that they have been optimised to a specific (UK) situation, and thus will always be different elsewhere. In addition, differences in methodology may contribute, especially with regard to the definition of "workload" and of two indicators. Workload is confined to the number of contacts in this analysis whereas Jarman's definition is, rightly, much broader. However, Ben-Shlomo's analysis generally confirms the ranking of Jarman's weights using a definition of workload which is rather similar to ours. ${ }^{4}$ Furthermore, two indicators differed. Differences were small for changing address, but potentially larger for housing quality: bad weatherproofing instead of overcrowding. In Amsterdam, both occur more frequently among young people, but overcrowding applies more specifically to young families. However, omission of both indicators from the analysis leads to even larger differences between our results and the Jarman weights. The large degree of difference in ranking of the various indicators is thus at least partly due to some real country-specific factors.

A more fundamental question is whether GPs should simply receive additional remuneration for current higher contact rates of certain patient groups or should be encouraged to develop new services for those who are underserved at present. A remuneration system which is completely based on current contact rates will not achieve the latter aim. Thus, part of the additional payments should ideally be aimed at developing additional services to meet, often regionally varying, unmet needs. ${ }^{20}$ In The Netherlands, GPs will probably receive higher remuneration for the increased workload due to sick fund insured patients from deprived areas, but not for privately insured patients for whom they receive a fee-for-service. However, probably one half of the entire amount will be used to fund specific local services aiming at the needs in these deprived areas. ${ }^{10}$

In conclusion, most of the Jarman indicators can be used at patient level, to predict the workload of an Amsterdam GP, and probably Dutch urban GP workload in general, but their relative weights should be adapted for this aim. Population research in other European coun- tries may show whether the Jarman index (indicators and attached weights) can be applied to urban areas in other countries with regard to the individual or the area level. If so, they may be useful as a basis for additional payments for GPs working in such deprived urban areas.

The fieldwork of this study was financially supported by the Amsterdam Municipal Coordinating Committee on Research $\mathrm{KKO}$, the Amsterdam Social Health Insurance Company ZAO, eight submunicipal authorities and the Municipal Health Department.

1 Jarman B. Identification of underprivileged areas. $B M \mathcal{F}$ 1983;286:1705-9.

2 Carr-Hill RA, Sheldon T. Designing a deprivation payment for general practitioners: the UPA (8) wonderland. $B M F$ 1991;302:393-6.

3 Talbot RJ. Underprivileged areas and health care planning implications of use of Jarman indicators of urban deprivation. $B M \mathcal{F}$ 1991;302:383-6.

4 Ben-Shlomo Y, White I, McKeigue PM. Prediction of general practice workload from census based social deprivation scores. F Epidemiol Community Health 1992;46: 532-6.

5 Jarman B, Bosanquet N. Primary health care in London changes since the Acheson report. BMf 1992;305:1130-6.

6 London Health Planning Consortium. Primary health care in inner London: report of a study group. London: Dein inner London: report of a study group. Londd

7 Wyke S, Campbell G, MacIver S. Provision of, and patien satisfaction with, the primary care services in a relatively satisfaction with, the primary care services in a relatively affluent area and a relatively

f Gen Pract 1992;42:271-5.
8 Kunst AE, Mackenbach JP. An international comparison of socio-economic inequalities in mortality. Rotterdam: Erasmus University, Department of Public Health and Social Medicine, 1992 .

9 Luitjen MCG, Tjadens FLJ. Huisartsen in achterstandswijken GPs in deprived neighbourhoods). Leiden: Research voo Beleid, 1995.

10 Joint Working Group on GP Care. Poortwachter in praktijk: rapportage van de Paritaire Werkgroep Huisartsenzorg over de rapportage van de Paritaire Werkgroep Huisartsenzorg over de plaats en financiering van de huisartsenzorg in ons land. Gatekeeper in practice: report of the Joint Working Group on GP Care on the siting and financing of GP care in
The Netherlands.) The Hague: Department of Public The Netherlands.) Welfare, and Sprots, 1995.

11 Rasch PC, Reijneveld SA, Van der Velden J. Identificatie van achterstandsgebieden: een systematiek voor de verdeling van middelen aan huisartsen. (Identification of deprived areas: a procedure for the allocation of resources to GPs.) Utrecht: LHV/KPZ/ZN, 1996.

12 Reijneveld SA. The impact of the Amsterdam aircraft disaster on reported annoyance by aircraft noise and on reported psychiatric disorders. Int $\mathcal{f}$ Epidemiol 1994;23. 333-40.

13 Cohen J. Statistical power analysis for the behavioral sciences. 2nd ed. Hillsdale, Lawrence Erlbaum Associates, 1988.

14 Norusis MJ. SPSS/PC + base system user's guide and advanced statistics. Version 5.0. Chicago: SPSS, 1992.

15 Netherlands Central Bureau of Statistics (NCBS). Neth erlands health interview survey 1981-1991. The Hague: NCBS, 1992.

16 Hastings A, Rashid A. General practice in deprived areas: problems and solutions (editorial). Br f Gen Pract 1993; 43:47-8, 51 .

17 Brouwer HJ, Mohrs J. Huisbezoek in de grote stad. (House call in the big city.) Huisarts $\mathcal{E}$ Wetenschap 1994;37:520-6.

18 Reijneveld SA. Causes of death contributing to urban socioeconomic mortality differences: evidence from Amsterdam, The Netherlands. Int $\mathcal{F}$ Epidemiol 1995;24:740-9.

19 Susser $M$. The logic in ecological fallacy: I The logic of analysis. Am f Public Health 1994;84:825-9.

20 Metcalfe D. Care in the capital: what needs to be done? BMF 1992;305:1141-4. 